\title{
Survival and failure trends of cerebrospinal fluid shunts with distal slit valves: comparative study and literature review
}

\author{
Jeremy S. Wetzel, MD, ${ }^{1}$ Alex D. Waldman, BS, ${ }^{1}$ Pavlos Texakalidis, MD, ${ }^{1}$ Bryan Buster, MD, ${ }^{1}$ \\ Sheila R. Eshraghi, MD, ${ }^{1}$ Jennifer Wheelus, NPC, ${ }^{2}$ Andrew Reisner, MD, ${ }^{2}$ and \\ Joshua J. Chern, MD, PhD²
}

'Department of Neurosurgery, Emory University School of Medicine, Atlanta; and 2Pediatric Neurosurgery Associates, Children's Healthcare of Atlanta, Georgia

OBJECTIVE The malfunction rates of and trends in various cerebrospinal fluid (CSF) shunt designs have been widely studied, but one area that has received little attention is the comparison of the peritoneal distal slit valve (DSV) shunt to other conventional valve $(\mathrm{CV})$ type shunts. The literature that does exist comes from older case series that provide only indirect comparisons, and the conclusions are mixed. Here, the authors provide a direct comparison of the overall survival and failure trends of DSV shunts to those of other valve type shunts.

METHODS Three hundred seventy-two new CSF shunts were placed in pediatric patients at the authors' institution between January 2011 and December 2015. Only ventriculoperitoneal (VP) shunts were eligible for study inclusion. Ventriculoatrial, lumboperitoneal, cystoperitoneal, subdural-peritoneal, and spinal shunts were all excluded. Rates and patterns of shunt malfunction were compared, and survival curves were generated. Patterns of failure were categorized as proximal failure, distal failure, simultaneous proximal and distal (proximal+distal) failure, removal for infection, externalization for abdominal pseudocyst, and addition of a ventricular catheter for loculated hydrocephalus.

RESULTS A total of 232 VP shunts were included in the final analysis, $115 \mathrm{DSV}$ shunts and $117 \mathrm{CV}$ shunts. There was no difference in the overall failure rate or time to failure between the two groups, and the follow-up period was statistically similar between the groups. The DSV group had a failure rate of $54 \%$ and a mean time to failure of 17.8 months. The CV group had a failure rate of $50 \%(p=0.50)$ and a mean time to failure of 18.5 months $(p=0.56)$. The overall shunt survival curves for these two groups were similar; however, the location of failure was significantly different between the two groups. Shunts with DSVs had proportionately more distal failures than the CV group (34\% vs $14 \%$, respectively, $p$ $=0.009)$. DSV shunts were also found to have proximal+distal catheter occlusions more frequently than CV shunts $(23 \%$ vs $5 \%$, respectively, $p=0.005$ ). CV shunts were found to have significantly more proximal failures than the DSV shunts $(53 \%$ vs $27 \%, p=0.028)$. However, the only failure type that carried a statistically significant adjusted hazard ratio in a multivariate analysis was proximal+distal catheter obstruction (CV vs DSV shunt: HR $0.21,95 \% \mathrm{Cl} 0.05-0.81$ ).

CONCLUSIONS There appears to be a difference in the location of catheter obstruction leading to the malfunction of shunts with DSVs compared to shunts with CVs; however, overall shunt survival is similar between the two. These failure types are also affected by other factors such etiology of hydrocephalus and endoscope use. The implications of these findings are unclear, and this topic warrants further investigation.

https://thejns.org/doi/abs/10.3171/2019.9.PEDS18579

KEYWORDS distal slit valve; cerebrospinal fluid shunt failure; shunt survival; shunt failure trends; hydrocephalus

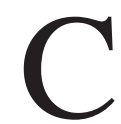
EREBROSPINAL fluid (CSF) shunts are the most commonly employed devices in pediatric neurosurgery. Many modifications and advances have been made in their design since the 1950s when the first sophisticated valves were designed. Despite advances in material sci- ence and valve designs, shunt malfunction remains a significant problem. Numerous studies have compared the failure rates of various types of shunt valves, but one area that has received little attention is the direct comparison of the peritoneal distal slit valve (DSV) to other conventional

ABBREVIATIONS CCC = complex chronic condition; $C S F=$ cerebrospinal fluid; $C V=$ conventional valve; $D S V=$ distal slit valve.

SUBMITTED September 18, 2018. ACCEPTED September 23, 2019.

INCLUDE WHEN CITING Published online December 13, 2019; DOI: 10.3171/2019.9.PEDS18579. 
valve $(\mathrm{CV})$ types in terms of shunt survival and patterns of failure.

DSVs have been around since the 1960s, and they gained popularity in the $1970 \mathrm{~s}$. When employed as the only valve mechanism on a shunt manufactured as a single piece, DSV shunts were believed to circumvent the problem of shunt disconnection as a mechanism of failure, which at the time was a significant concern. ${ }^{7}$ Additionally, a single-piece shunt system facilitated placement as there were fewer separate pieces that required assembly, thereby reducing operating time and theoretically the risk of infection. Several years after the widespread adoption of this valve design, reports of overdrainage syndromes were tied to these valves, which led to a decrease in their use, though this relationship was never convincingly demonstrated in the literature. ${ }^{4,5}$

The few studies that have addressed DSVs in terms of their failure trends have done so indirectly, and most are over 20 years old. Furthermore, they have produced mixed results. Through a series of papers from 1989 to 1991, Sainte-Rose and colleagues were the first to demonstrate a difference in failure pattern among shunts with DSVs and shunts with proximal nonslit valves. ${ }^{7}$ These authors reported a significantly lower overall rate of failure with nonslit valves and a significantly higher rate of distal occlusion with peritoneal DSVs. Their study remains the most thorough direct assessment of this valve design we have to date. Other studies have reported no difference in the failure rate or pattern regardless of the valve design used, but the number of slit valve shunts included in these studies is typically small, and none of these studies are a satisfactory direct comparison..$^{1,3-5}$

Shunts with DSVs are still in use today, and because of the conflicting conclusions among a small number of studies, we believe more investigation is needed. Here, we present a retrospective modern surgical series directly comparing the malfunction rates and patterns of failure of DSV shunts to those of shunts with other valve types, and we review the available literature. The impetus to perform this study was to ascertain a difference in failure patterns and, if one exists, to perhaps serve as a starting point for future study of mechanisms underlying proximal and distal shunt malfunction.

\section{Methods}

Approval for this retrospective cohort study was obtained from the Institutional Review Board of Children's Healthcare of Atlanta. Three hundred seventy-two CSF shunts were placed in pediatric patients at our institution between January 2011 and December 2015 and were considered for study inclusion. Electronic medical records (EMRs) were instituted in 2010, which explains why this starting date was chosen. The operative notes for the insertion and revision surgeries were pulled from the EMRs for each patient. Only first-time failures following initial shunt placements were examined. All surgeries were performed by 5 board-certified or board-eligible pediatric neurosurgeons in our practice. Shunts were considered to have failed if the patient had any surgery to revise, manipulate, or remove the shunt system; there was no failure if there had been no revision surgery up to the time of the last follow-up. Things like removal for infection and externalization for an abdominal pseudocyst prompted revision surgeries. Cases in which there was no follow-up documentation after shunt placement were excluded. The findings dictated in the operative note were used to determine the location of failure. We did not have any cases of definitively negative exploration in this series. Only ventriculoperitoneal shunts were included in the final analysis; ventriculoatrial, lumboperitoneal, cystoperitoneal, subdural, and spinal shunts were excluded. Rates and patterns of shunt malfunction were compared, and survival curves were generated. Patterns of failure were categorized as proximal failure, distal failure, simultaneous proximal and distal (proximal+distal) failure, removal for infection, externalization for abdominal pseudocyst, and addition of a ventricular catheter for loculated hydrocephalus.

\section{Statistical Analysis}

Continuous data were presented as the mean \pm standard deviation, while categorical data were expressed as absolute numbers and relative frequencies. A Cox proportional hazards regression model was used for univariate and multivariate analyses. Hazard ratios with corresponding 95\% confidence intervals were provided for all analyses. The dependent variables were proximal, distal, and proximal+distal shunt malfunction. The following variables were decided a priori to be included in the multivariate model: shunt type, hydrocephalus etiology, intraoperative guidance, entry point, cardiac complex chronic condition (CCC), and age. The Kaplan-Meier method was used to generate survival curves, and the log-rank test was used to compare the curves of the DSV versus CV shunts. Time to failure was compared using the Wilcoxon rank-sum test. The Fisher exact and chi-square tests were used to compare categorical variables as appropriate. The threshold for statistical significance was $p<0.05$. The Stata statistical package was used for all analyses (version 14.1, StataCorp LLC).

\section{Results}

Of the 372 CSF shunts placed, 251 were ventriculoperitoneal shunts and were therefore eligible for initial inclusion in our analysis. One hundred twenty patients underwent shunt placement with a DSV system (Codman Uni-Shunt, Integra LifeSciences), and 131 underwent placement with CV types. The CV types consisted primarily of fixed-pressure Delta and PS Medical valves (Medtronic) but also included a few Medtronic Strata II and Aesculap proGav programmable valves. The groups were categorized dichotomously into DSV shunts and CV shunts. Figure 1 is a CONSORT diagram outlining inclusion and exclusion parameters in our series.

Initial data analysis revealed a statistically significant variance between the two shunt groups with respect to categorical patient age as very few Uni-Shunts were placed in patients older than 10 years of age. For a more direct comparison of the groups, an additional 19 patients were excluded (Fig. 1), 14 patients with ages greater than 10 years and 5 patients for whom there was incomplete in- 


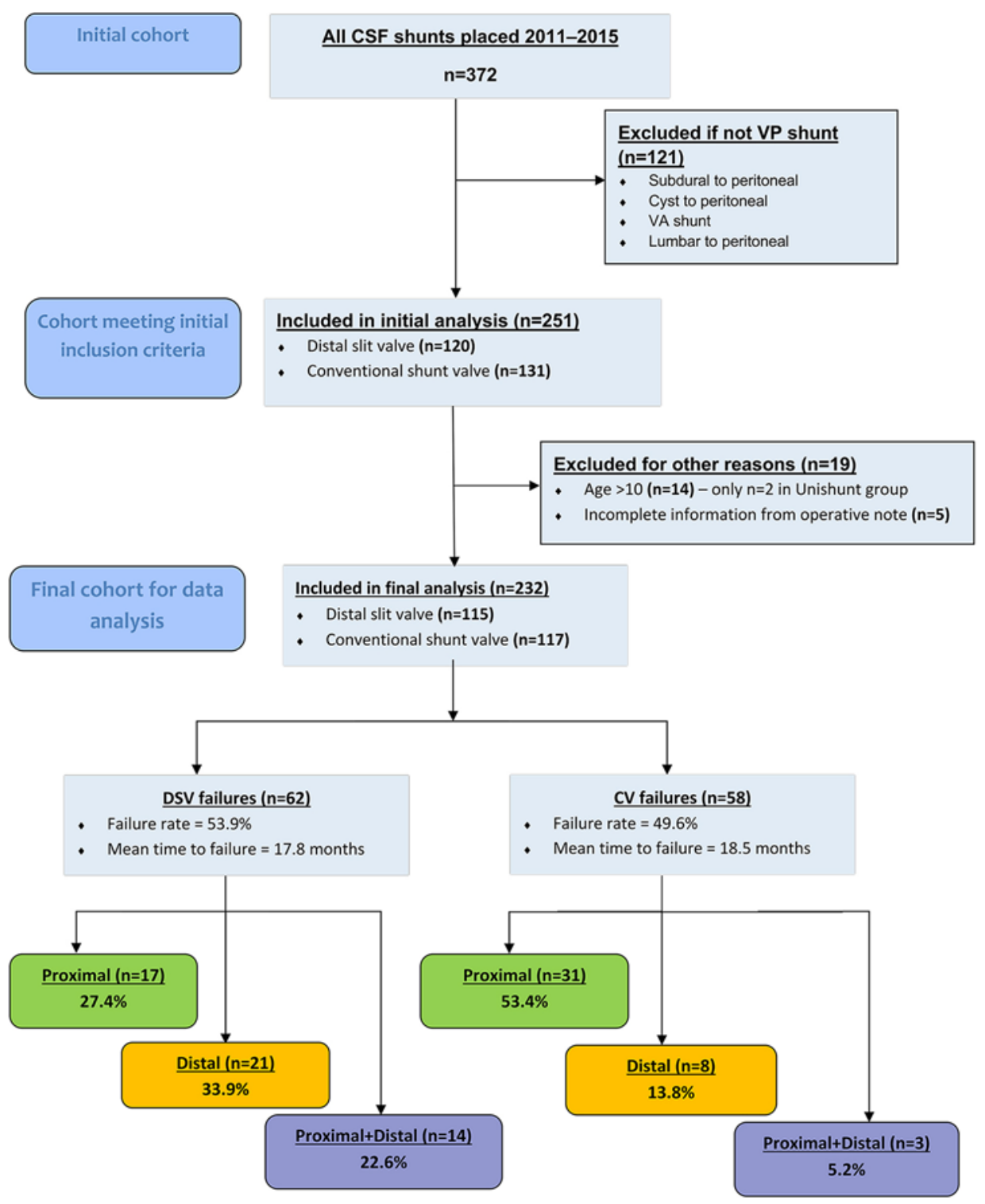

FIG. 1. CONSORT flow diagram. VA = ventriculoatrial. Figure is available in color online only.

formation in the chart or operative note. Thus, a total of 115 DSV shunts and $117 \mathrm{CV}$ shunts were included in the final analysis.

\section{Overall Shunt Survival and Time to Failure}

Table 1 shows the characteristics of the 232 patients included in the final analysis. The two groups were statistically similar in terms of age, sex, and presence of a cardiac $\mathrm{CCC}$, but there were statistical differences in the etiology of hydrocephalus, the cranial entry point, and whether an endoscope was used. These differences are further examined in a multivariate model, discussed below.

The overall rate of shunt failure in the DSV group was not significantly different from that in the CV group $(53.9 \%$ vs $49.6 \%$, respectively). These rates represent all types of failure including revision surgery for reasons other than shunt catheter blockage (Table 2). The mean time to fail- ure was 17.8 months in the DSV group and 18.5 months in the $\mathrm{CV}$ group $(\mathrm{p}=0.56)$. The survival curves for any shunt failure are shown in Fig. 2 and were not statistically different between the two groups over the follow-up period ( $\mathrm{p}=$ 0.95 ). The mean follow-up time for all patients in the study was 2.3 years in the DSV group and 2.0 years in the $\mathrm{CV}$ group and was not statistically different.

\section{Modes of Failure-Univariate Analysis}

The patterns of shunt failure are shown in Table 2. Of the 62 total shunt failures in the DSV group, $27.4 \%$ were proximal obstructions, $33.9 \%$ were distal obstructions, and $22.6 \%$ were proximal+distal catheter obstructions. The remaining shunt failures in this group $(16.1 \%)$ were attributable to something other than a catheter blockage. Six DSV shunts were removed for infection, 2 were externalized for an abdominal pseudocyst, 1 required the addition of a ven- 
TABLE 1. Characteristics of 232 patients with ventriculoperitoneal shunts

\begin{tabular}{|c|c|c|c|}
\hline \multirow[b]{2}{*}{ Variable } & \multicolumn{2}{|c|}{ №. $(\%)$} & \multirow{2}{*}{$\begin{array}{c}p \\
\text { Value }\end{array}$} \\
\hline & DSV Shunt & CV Shunt & \\
\hline No. of patients & 115 & 117 & \\
\hline Age category & & & 0.28 \\
\hline$<1 \mathrm{mo}$ & $52(45.2)$ & $48(41)$ & \\
\hline $1-12$ mos & $45(39.1)$ & $41(35)$ & \\
\hline $1-10 \mathrm{yrs}$ & $18(15.7)$ & $28(24)$ & \\
\hline Female sex & $53(46)$ & $50(42.7)$ & 0.60 \\
\hline Etiology of hydrocephalus & & & 0.01 \\
\hline IVH of prematurity & $36(31.3)$ & $27(23)$ & \\
\hline Myelomeningocele & $6(5.2)$ & $5(4.3)$ & \\
\hline Aqueductal stenosis & $21(18.3)$ & $6(5.1)$ & \\
\hline Tumor & $6(5.2)$ & $15(12.8)$ & \\
\hline Infection & $6(5.2)$ & $5(4.3)$ & \\
\hline Trauma & $3(2.6)$ & $4(3.4)$ & \\
\hline Congenital/other & $37(32.2)$ & $55(47)$ & \\
\hline Valve type & & & NA \\
\hline PS Medical & NA & $65(55.5)$ & \\
\hline Delta & NA & $35(30)$ & \\
\hline Programmable & NA & $17(14.5)$ & \\
\hline Cranial entry point & & & 0.001 \\
\hline Frontal & $5(4.3)$ & $26(22.2)$ & \\
\hline Parietal & $110(95.7)$ & $91(77.8)$ & \\
\hline Intraop adjuncts used & & & $<0.001$ \\
\hline None & $113(98.3)$ & $100(85.5)$ & \\
\hline Endoscope & $2(1.7)$ & $17(14.5)$ & \\
\hline Cardiac CCC & & & 0.84 \\
\hline Yes & $26(22.6)$ & $25(21.4)$ & \\
\hline No & $89(77.4)$ & $92(78.6)$ & \\
\hline
\end{tabular}

$\mathrm{IVH}=$ intraventricular hemorrhage; NA = not applicable.

tricular catheter for complex loculated hydrocephalus, and 1 was removed for iatrogenic intraventricular hemorrhage related to catheter manipulation during revision. Of the 58 total failures in the CV group, $53.4 \%$ failed proximally, $13.8 \%$ failed distally, and only $5.2 \%$ failed both proximally and distally. Six shunts (10.3\%) had valves that were the source of malfunction. In 2 of these cases, the valve was found to be the location of obstruction, and in the other 4 , the valve was changed for presumed overshunting. The remaining failures in this group (17.2\%) were related to infection or a pseudocyst or required the addition of a ventricular catheter to the shunt system. There was a statistically significant difference in the location of catheter obstruction leading to shunt failure between the two groups, but no difference in the rates of other sources of failure (Table 2). Uni-Shunts appeared to have proportionately higher rates of distal and proximal+distal shunt failures, while CV shunts had more proximal failures. Shunt survival curves for the time to proximal, distal, and proximal+distal failures were all significantly different between the two groups and are shown in Fig. 2.
TABLE 2. Shunt failure summary

\begin{tabular}{lccc}
\hline \multicolumn{1}{c}{ Variable } & DSV Shunt & CV Shunt & p Value \\
\hline Total failed shunts & $62(53.9 \%)$ & $58(49.6 \%)$ & 0.50 \\
\hline Proximal obstruction & $17(27.4 \%)$ & $31(53.4 \%)$ & 0.028 \\
\hline Distal obstruction & $21(33.9 \%)$ & $8(13.8 \%)$ & 0.009 \\
\hline Proximal+distal obstruction & $14(22.6 \%)$ & $3(5.2 \%)$ & $\mathbf{0 . 0 0 5}$ \\
\hline Valve & $0(0 \%)$ & $2(3.4 \%)$ & 0.49 \\
\hline Pseudocyst & $2(3.2 \%)$ & $5(8.6 \%)$ & 0.44 \\
\hline Infection & $6(9.7 \%)$ & $3(5.2 \%)$ & 0.33 \\
\hline Addition of catheter & $1(1.6 \%)$ & $2(3.4 \%)$ & 1.0 \\
\hline Other & $1(1.6 \%)^{*}$ & $4(6.9 \%) \dagger$ & 0.36 \\
\hline
\end{tabular}

Boldface type indicates statistical significance.

${ }^{*}$ Removal for iatrogenic intraventricular hemorrhage.

† Valve changed for overshunting.

Univariate Cox proportional hazard ratios were generated for each of these 3 outcomes and are shown in Supplemental Tables 1-3. CV shunts carried an unadjusted HR of 1.97 (95\% CI 1.09-3.57) for a proximal failure. The hydrocephalus etiology of brain tumor and the use of an endoscope were also associated with proximal malfunction (unadjusted HR 2.95, 95\% CI 1.00-8.69 and unadjusted HR 2.36, 95\% CI 1.10-5.06, respectively; Supplemental Table 1). CV shunts had a statistically significant lower risk for distal failure (unadjusted HR $0.43,95 \% \mathrm{CI}$ 0.19-0.99), as did the etiology of congenital hydrocephalus (unadjusted HR 0.17, 95\% CI 0.06-0.54; Supplemental Table 2). Lastly, CV shunts were associated with a significantly lower risk for proximal+distal failure (unadjusted HR 0.22, 95\% CI 0.06-0.78; Supplemental Table 3).

\section{Modes of Failure-Multivariate Analysis}

A multivariate Cox proportional regression analysis was also performed for the same 3 shunt outcomes, and Tables 3-5 show these results. Shunt type was no longer a predictor of proximal failure, but brain tumor as an etiology remained significant (adjusted HR 4.89, 95\% CI 1.11-21.55; Table 3). Shunt type was also no longer significantly associated with the outcome of distal shunt failure, whereas congenital hydrocephalus as an etiology remained significant (adjusted HR 0.15, 95\% CI 0.04-0.53; Table 4). Finally, DSV shunts were an independent predictor of proximal+distal failure. The adjusted HR for CV shunts was 0.21 (95\% CI 0.05-0.81) for proximal+distal malfunction (Table 5).

\section{Discussion and Review of the Literature}

Here, using a retrospective study design, we reported on the survivability and failure trends of shunts with DSVs compared to shunts with other valve types. Our results showed that there is no difference in overall shunt survival, but there seems to be a difference in the location of catheter occlusion leading to malfunction. The observation that overall shunt survival is similar between DSV and $\mathrm{CV}$ shunts is consistent with findings in other major studies comparing various shunt valve types.?

The limitations of this study include its retrospective 

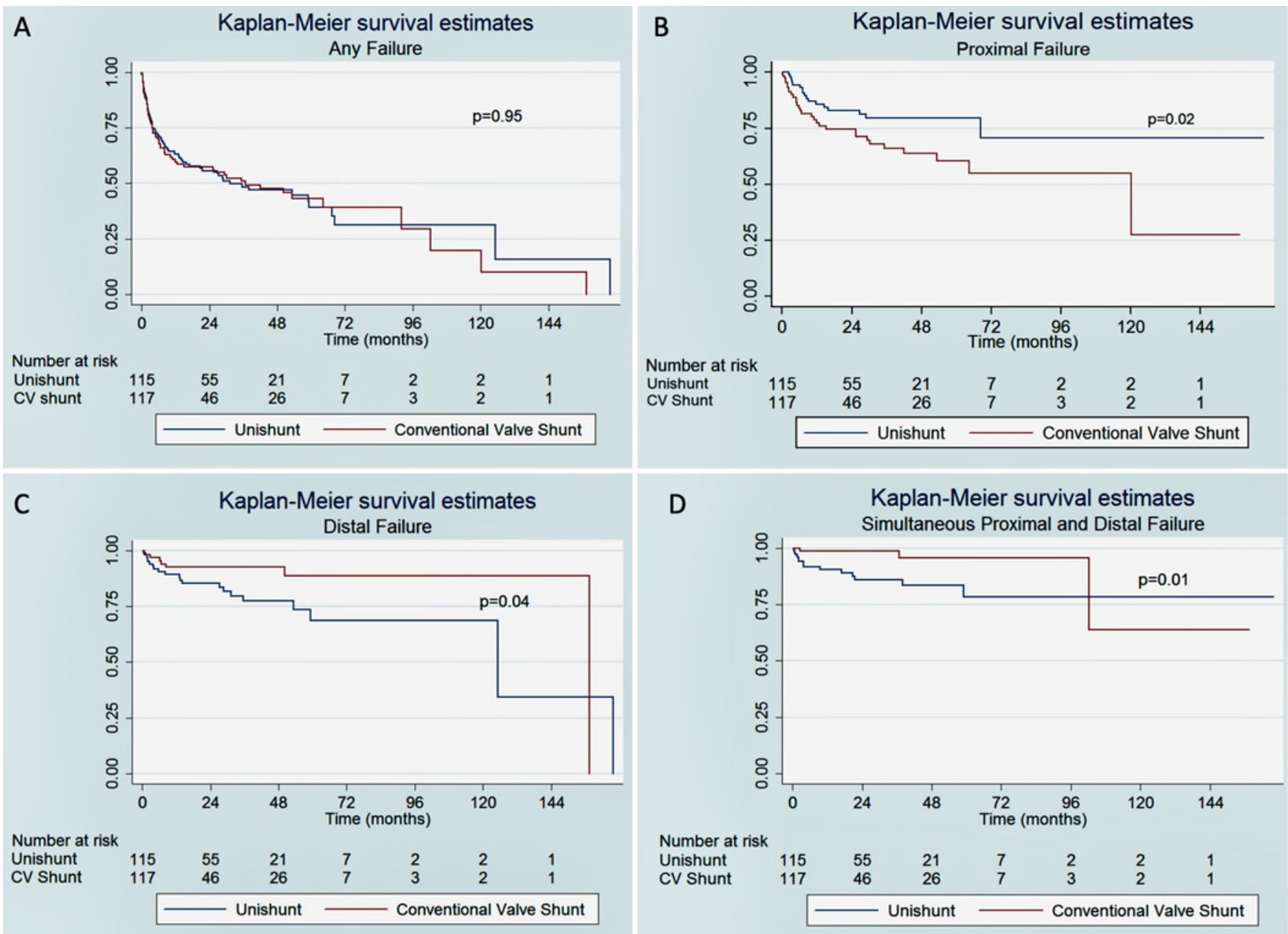

FIG. 2. Kaplan-Meier shunt survival curve analysis comparing Uni-Shunts to CV shunts. A: Time to any shunt failure. B: Time to proximal shunt failure. C: Time to distal shunt failure. D: Time to proximal+distal shunt failure. Figure is available in color online only.

design and the fact that there were statistically significant differences between the two groups with respect to factors such as hydrocephalus etiology, entry point, and the use of an endoscope. We believe these differences are, in part, attributable to the relatively small numbers of patients in certain subcategories.

We believe that the slight differences between the groups that did reach statistical significance do not account for the differences seen in the failure pattern. There was a higher proportion of frontal catheters in the CV group but still more parietal shunts overall in both groups. There were more cases in which an endoscope was used during shunt placement in the CV group. Most of these differences occurred in categories in which there were relatively few patients, making it more likely for small differences to reach statistical significance. The subcategories containing the majority of patients for each characteristic did not reach statistical significance.

Shunts with closed-ended DSVs (Codman Uni-Shunts in our study) have a higher rate of distal catheter occlusion as well as shunt failures where both proximal and distal catheters are occluded. Uni-Shunts were an independent predictor of simultaneous proximal and distal occlusion in the multivariate model. The reason for this is unknown, but it seems logical that occlusion of two separate portions of the system would happen consecutively rather than simultaneously. It is possible that the distal end slowly occludes first, causing sluggish flow through the proximal catheter, and that this relative stasis of CSF flow makes it more likely to have choroid plexus protein accumulation and subsequent proximal catheter occlusion. It is likely that omentum gets caught in the slits, which are opening and closing periodically, related to pressure differentials. It has been speculated in numerous papers that proximity to the choroid plexus and higher CSF protein levels contribute to proximal catheter occlusion. ${ }^{8}$ It is not surprising that the DSV shunts would have more distal malfunctions, but we would expect the proximal catheters to become occluded at an equal rate in both groups, leading to a higher overall failure rate in the DSV group, but this was not the case. The reason for this is unknown. Finally, the fact that simultaneous proximal and distal occlusions retained a statistically significant difference in the multivariate analysis should be interpreted cautiously, as the relative event rate was small in this series compared to that for other patterns of failure. 
TABLE 3. Association between variables and the outcome of time to proximal shunt failure: multivariate Cox proportional hazards regression analysis

\begin{tabular}{lccc}
\hline \multicolumn{1}{c}{ Variable } & Adjusted HR & $\mathrm{LCl}$ & $\mathrm{UCl}$ \\
\hline Shunt type (CV vs Uni-Shunt) & 1.77 & 0.92 & 3.40 \\
\hline Hydrocephalus etiology & & & \\
\hline IVH & Reference & - & - \\
\hline Myelomeningocele & 1.29 & 0.32 & 5.15 \\
\hline Aqueductal stenosis & 0.78 & 0.23 & 2.60 \\
\hline Tumor & 4.89 & 1.11 & 21.55 \\
\hline Prematurity-no IVH & 2.96 & 0.28 & 31.06 \\
\hline Congenital & 1.17 & 0.54 & 2.55 \\
\hline Postinfectious & 1.40 & 0.40 & 4.84 \\
\hline TBI & 0.75 & 0.09 & 6.05 \\
\hline Use of endoscope & 2.18 & 0.86 & 5.50 \\
\hline Entry point (parietal vs frontal) & 1.84 & 0.67 & 5.03 \\
\hline Cardiac CCC & 1.13 & 0.54 & 2.36 \\
\hline Age & & & \\
\hline $0-1$ mo & Reference & - & - \\
\hline 1-12 mos & 0.64 & 0.32 & 1.27 \\
\hline$>12$ mos & 0.41 & 0.12 & 1.35 \\
\hline
\end{tabular}

$\mathrm{LCl}=$ lower confidence interval; $\mathrm{TBI}$ = traumatic brain injury; $\mathrm{UCl}=$ upper confidence interval.

Boldface type indicates statistical significance.

TABLE 4. Association between variables and the outcome of time to distal shunt failure: multivariate Cox proportional hazards regression analysis

\begin{tabular}{lccc}
\hline \multicolumn{1}{c}{ Variable } & Adjusted HR & $\mathrm{LCl}$ & $\mathrm{UCl}$ \\
\hline Shunt type (CV vs Uni-Shunt) & 0.63 & 0.25 & 1.55 \\
\hline Hydrocephalus etiology & & & \\
\hline IVH & Reference & - & - \\
\hline Myelomeningocele & 0.83 & 0.17 & 4.10 \\
\hline Aqueductal stenosis & 0.60 & 0.19 & 1.87 \\
\hline Tumor & 0.18 & 0.01 & 1.74 \\
\hline Prematurity-no IVH & $\mathrm{NA}$ & $\mathrm{NA}$ & $\mathrm{NA}$ \\
\hline Congenital & 0.15 & 0.04 & 0.53 \\
\hline Postinfectious & 0.67 & 0.08 & 5.34 \\
\hline TBI & $\mathrm{NA}$ & $\mathrm{NA}$ & $\mathrm{NA}$ \\
\hline Use of endoscope & $\mathrm{NA}$ & $\mathrm{NA}$ & $\mathrm{NA}$ \\
\hline Entry point (parietal vs frontal) & 1.06 & 0.31 & 3.58 \\
\hline Cardiac CCC & 1.07 & 0.40 & 2.84 \\
\hline Age & & & \\
\hline $0-1$ mo & Reference & - & - \\
\hline $1-12$ mos & 1.32 & 0.53 & 3.33 \\
\hline$>12$ mos & $\mathbf{5 . 6 2}$ & 1.86 & 17.01 \\
\hline
\end{tabular}

Boldface type indicates statistical significance.

At our institution, the vast majority of DSV shunts are placed by 2 of the 5 surgeons in our practice, and shunt placements occurred exclusively at one of the two pediatric neurosurgery centers in our practice. The differences seen between the two shunt groups likely reflect a varia-
TABLE 5. Association between variables and the outcome of time to simultaneous proximal and distal shunt failure: multivariate Cox proportional hazards regression analysis

\begin{tabular}{lccc}
\hline \multicolumn{1}{c}{ Variable } & Adjusted HR & $\mathrm{LCl}$ & $\mathrm{UCl}$ \\
\hline Shunt type (CV vs Uni-Shunt) & $\mathbf{0 . 2 1}$ & $\mathbf{0 . 0 5}$ & $\mathbf{0 . 8 1}$ \\
\hline Hydrocephalus etiology & & & \\
\hline IVH & Reference & - & - \\
\hline Myelomeningocele & 0.41 & 0.04 & 3.55 \\
\hline Aqueductal stenosis & 0.16 & 0.01 & 1.39 \\
\hline Tumor & $\mathrm{NA}$ & $\mathrm{NA}$ & $\mathrm{NA}$ \\
\hline Prematurity-no IVH & $\mathrm{NA}$ & $\mathrm{NA}$ & $\mathrm{NA}$ \\
\hline Congenital & 0.73 & 0.06 & 8.06 \\
\hline Postinfectious & 1.40 & 0.40 & 4.84 \\
\hline TBI & $\mathrm{NA}$ & $\mathrm{NA}$ & $\mathrm{NA}$ \\
\hline Use of endoscope & 1.59 & 0.13 & 19.10 \\
\hline Entry point (parietal vs frontal) & 1.56 & 0.19 & 12.63 \\
\hline Cardiac CCC & 0.35 & 0.07 & 1.61 \\
\hline Age & & & \\
\hline $0-1$ mo & Reference & - & - \\
\hline 1-12 mos & 0.65 & 0.22 & 1.87 \\
\hline$>12$ mos & 0.57 & 0.06 & 4.85 \\
\hline
\end{tabular}

Boldface type indicates statistical significance.

tion in practice pattern or the types of pathologies seen at each of the two centers, though in general all types of pathologies are seen at both centers. Surgeon preference was the sole determinant for what type of shunt was placed in each patient. Two of the surgeons utilize DSV shunts nearly exclusively, but they are more likely to place another valve type in older patients, which is one possible reason that there was a significant difference between the groups in the patients older than 10 years.

The possible advantages of a DSV shunt include its fewer components and therefore fewer things to assemble at the time of operation, which would theoretically reduce operating times. There are fewer connection points; therefore, disconnection may be less likely. The tapping reservoir on these shunts tends to have a slightly lower profile than even the "low-profile" valves on the market, which is desirable, particularly in infants. Lastly, in the case of an isolated distal occlusion, the belly can be opened, the distal catheter removed, and the slit valve cleared of debris. It is typical to find a proteinaceous "plug" occluding the closed-ended catheter tip. When this is removed, in the majority of cases brisk flow is restored and the distal catheter can simply be reinserted without the need to expose or manipulate any other portion of the shunt system. In this common scenario, it is our practice to prep out all incisions, and then a tap of the reservoir is performed sterilely. If there is proximal flow, the abdominal incision is opened first and the tip of the distal catheter is examined.

\section{Summary of Past Studies}

Other studies have yielded findings similar to ours. Table 6 presents a summary of studies evaluating the malfunction of shunts with DSVs. In 1994 Hahn compared 
TABLE 6. Summary of studies evaluating malfunction of shunts with DSVs

\begin{tabular}{|c|c|c|c|c|c|}
\hline \multirow[b]{2}{*}{ Variable } & \multicolumn{5}{|c|}{ Authors \& Year } \\
\hline & $\begin{array}{c}\text { Sainte-Rose et al., } \\
\text { 1991-1992 }\end{array}$ & $\begin{array}{l}\text { Hahn, } \\
1994\end{array}$ & $\begin{array}{c}\text { Cozzens \& Chandler, } \\
1997\end{array}$ & $\begin{array}{l}\text { Virella et al., } \\
2002\end{array}$ & Present Study \\
\hline No. of patients & 1719 & 155 & 166 (372 operations) & 141 & 232 \\
\hline$\%$ DSV & $56.2 \%$ & $100 \%$ & NR & $28.4 \%$ & $49.5 \%$ \\
\hline Total failure rate & $30 \%$ at $1 \mathrm{yr}, 70 \%$ at $10 \mathrm{yrs}$ & $30.3 \%$ at 2 yrs & NR & 31\% (DSV), 30\% (Delta) & $54 \%$ (DSV), 50\% (CV) \\
\hline $\begin{array}{l}\text { Proportion of } \\
\text { failures due to } \\
\text { obstruction }\end{array}$ & $56.1 \%$ & $96.3 \%$ & $83 \%$ & NR (either group) & $84 \%$ (DSV), $72 \%$ (CV) \\
\hline $\begin{array}{l}\% \text { proximal } \\
\text { failures }\end{array}$ & $30.2 \%$ & $33.1 \%$ & $77.1 \%$ & $61.3 \%$ (DSV), 80\% (Delta) & $27.4 \%$ (DSV), $53.4 \%$ (CV) \\
\hline$\%$ distal failures & $13.6 \%$ & $42.6 \%$ & $12.1 \%$ & $25.8 \%$ (DSV), 5\% (Delta) & $33.9 \%$ (DSV), $13.8 \%$ (CV) \\
\hline $\begin{array}{l}\% \text { proximal+distal } \\
\text { failures }\end{array}$ & $8 \%{ }^{*}$ & $14.7 \%$ & $10 \%$ & NR (DSV), 5\% (Delta) & $22.6 \%(\mathrm{DSV}), 5.2 \%$ (CV) \\
\hline $\begin{array}{l}\text { Direct compari- } \\
\text { son of DSV \& } \\
\text { other valve? }\end{array}$ & $\begin{array}{l}\text { Yes, but location of failure } \\
\text { according to group NR; } \\
\text { only survival curves } \\
\text { showing differences } \\
\text { btwn groups given }\end{array}$ & $\begin{array}{l}\text { All patients had } \\
\text { DSV shunts; } \\
\text { no comparison } \\
\text { group }\end{array}$ & $\begin{array}{l}\text { No; there is a comparison } \\
\text { group but comparisons } \\
\text { are indirect \& difficult to } \\
\text { interpret }\end{array}$ & $\begin{array}{l}\text { Yes, but } p \text { value data not } \\
\text { given on differences } \\
\text { in failure location, only } \\
\text { total failure }\end{array}$ & Yes \\
\hline $\begin{array}{l}\text { Summary of rel- } \\
\text { evant findings }\end{array}$ & $\begin{array}{l}\text { Parallel survival curves } \\
\text { but reduced OS } \\
\text { of shunts w/ DSVs } \\
\text { compared to proxi- } \\
\text { mal nonslit valves; } \\
\text { distal malfunction } \\
\text { more likely w/ closed- } \\
\text { ended distal cath- } \\
\text { eters w/ slits than w/ } \\
\text { open-ended catheters }\end{array}$ & $\begin{array}{l}\text { Study only offers } \\
\text { failure data for } \\
155 \text { patients w/ } \\
\text { "double DSVs"; } \\
\text { distal obstruc- } \\
\text { tions much } \\
\text { more common } \\
\text { than proximal }\end{array}$ & $\begin{array}{l}\text { Study examined } 168 \\
\text { revision surgeries of } \\
166 \text { patients; } 140 \text { cases } \\
\text { due to obstruction-85 } \\
(60.7 \%) \text { of those were } \\
\text { in patients w/ DSVs; } 31 \\
\text { cases of distal obstruc- } \\
\text { tion, all of which had } \\
\text { DSVs; comparison of } \\
\text { proportions of location } \\
\text { of failure not provided }\end{array}$ & $\begin{array}{l}\text { Total failure rate equal } \\
\text { btwn } 2 \text { groups; vast } \\
\text { majority of failures in } \\
\text { Delta valve group were } \\
\text { proximal w/ very few } \\
\text { distal malfunctions; } \\
\text { more distal malfunc- } \\
\text { tions in DSV group, but } \\
\text { p value not provided }\end{array}$ & $\begin{array}{l}\text { OS not different btwn } \\
\text { DSV \& CV shunts; } \\
\text { more proximal failures } \\
\text { in CV shunts; more dis- } \\
\text { tal \& combined failures } \\
\text { in DSV shunts }\end{array}$ \\
\hline
\end{tabular}

$\mathrm{NR}=$ not reported; $\mathrm{OS}=$ overall survival.

*Eight percent reported as "undefined obstruction," but unclear how much of this included a double obstruction of proximal and distal catheters.

the failure trends of two different types of DSV shunts but did not have a comparison group without DSVs. ${ }^{6}$ The most common location of obstruction in his study was distal, comprising $42.6 \%$ of all failures. Obstruction was proximal in $33.1 \%$ and both proximal and distal in $14.7 \%$. This pattern of failure is similar to the pattern seen in our DSV group. Otherwise, Hahn's study focuses more on the issue of overdrainage and so-called slit ventricle syndrome (SVS) than on the issue of the location of shunt occlusion.

Sainte-Rose et al. conducted a very thorough retrospective analysis of 1719 patients with various types of shunts and an average 12-year follow-up. ${ }^{7}$ The failure rate was $81 \%$ over 12 years. The patient cohort consisted of 2 groups, one with DSVs (56\%) and the other with proximal nonslit valves. These authors found that $56 \%$ of all failures were attributable to catheter obstruction at some location. The other causes included pseudocysts, catheter fractures, disconnections, overdrainage, and skin erosion. Of the failures caused by obstruction, $30.2 \%$ were proximal, $13.6 \%$ distal, and $8 \%$ "undefined." Unfortunately, the authors do not break this latter category down by location of obstruction based on valve types, but they do present shunt survival data suggesting that distal failure was more likely with a DSV. Their data also suggested that the overall failure rate was higher with DSVs. These differences in shunt survival reached statistical significance. Our cohort differed substantially in that $84 \%$ and $72 \%$ of shunt failures were attributable to obstruction in the DSV and CV groups, respectively. Sainte-Rose and colleagues had significantly more failures due to shunt disconnection and catheter fracture. The reason for this finding is not clear, but it could be explained by improvements in the catheter and shunt design.

Although it was not the primary focus of their study, Cozzens and Chandler addressed this issue indirectly in $1997 .{ }^{2}$ They reviewed 140 cases of shunt revision due to obstruction, which included 85 cases in which a DSV was involved. The overall rates of proximal, distal, and proximal+distal shunt failure were $77.1 \%, 12.1 \%$, and $10 \%$, respectively; however, they do not report these rates as a function of the shunt valve design. The authors state that there was some form of DSV in 100\% of the cases in which the distal end of the shunt was involved. They also report that among those cases without a DSV, no distal occlusions were found. What we do not know is what proportion of cases with DSVs had proximal obstructions or what proportion of total obstruc- 
tions were attributable to each group of patients. Therefore, complete conclusions cannot be made about the patterns of failure as a function of valve type.

Virella et al. examined DSV shunts in 2002, and although the primary objective of their study was to evaluate the incidence of overdrainage, they also compared the failure rates and patterns of 101 patients with DVS shunts to those of 40 patients with Delta valves, finding no difference in overall failure between the groups. ${ }^{8}$ First-time failure rates were $31 \%$ for the DSV group and $30 \%$ for the Delta valve group, which was consistent with our findings of no overall difference in failure rate. In the DSV group, $61 \%$ of first-time failures were proximal and $26 \%$ were distal. In the Delta valve group, they only report the pattern of failure overall, which included first and second failures in the same patients, for which the proximal failure rate was $80 \%$ and the distal rate was $5 \%$. Again, here the comparisons are indirect, and the numbers are relatively small between the groups, making it difficult to draw conclusions.

A prospective randomized trial demonstrated no difference in failure rates between the most commonly used shunt valves; ${ }^{3}$ however, DSVs were not included in that study, so we believed the question deserved exploration. As the failure rates of these two categories of valves, DSVs and CVs, are not statistically different, we can conclude that they are equally effective and durable in achieving the primary goal of CSF diversion for the same period of time. Nonetheless, the difference in catheter occlusion site does have potential implications in terms of surgical morbidity. Shunt revision surgery carries risks that are associated with the site of obstruction. For proximal revisions, risks include intracerebral and intraventricular hemorrhage, catheter misplacement, or catheter loss, just to name a few. In the case of distal revision, there are times when it can be difficult to guide the catheter back down the same tract and a new laparotomy is required, and other times laparoscopy and the assistance of a general surgeon are needed. And in the case of proximal and distal occlusion, both ends of the shunt must be manipulated, operating times are longer, and there are two incisions, logically increasing the inherent risk of infection.

\section{Conclusions}

Our study shows that the overall survival of shunts with DSVs and other valve types is no different but that the way in which these two types of shunts fail is different. No recommendations can be made about which type of valve should be used. In fact, according to our results, they perform equally well at the single most important objective, that is, CSF diversion for as long as possible. The difference in failure patterns, however, may have implications in terms of the risk associated with shunt revision surgery since different maneuvers are required for proximal versus distal revisions. Most importantly, in cases in which both the proximal and distal catheters need to be manipulated, both incisions must be opened, requiring longer operating times and risking higher blood loss. Further investigation with larger studies is needed to evaluate these relationships.

\section{References}

1. Blount JP, Campbell JA, Haines SJ: Complications in ventricular cerebrospinal fluid shunting. Neurosurg Clin N Am 4:633-656, 1993

2. Cozzens JW, Chandler JP: Increased risk of distal ventriculoperitoneal shunt obstruction associated with slit valves or distal slits in the peritoneal catheter. J Neurosurg 87:682-686, 1997

3. Drake JM, Kestle JR, Milner R, Cinalli G, Boop F, Piatt J Jr, et al: Randomized trial of cerebrospinal fluid shunt valve design in pediatric hydrocephalus. Neurosurgery 43:294-305, 1998

4. Epstein F, Lapras C, Wisoff JH: 'Slit-ventricle syndrome': etiology and treatment. Pediatr Neurosci 14:5-10, 1988

5. Epstein F, Marlin AE, Wald A: Chronic headache in the shunt-dependent adolescent with nearly normal ventricular volume: diagnosis and treatment. Neurosurgery 3:351-355, 1978

6. Hahn YS: Use of the distal double-slit valve system in children with hydrocephalus. Childs Nerv Syst 10:99-103, 1994

7. Sainte-Rose C, Piatt JH, Renier D, Pierre-Kahn A, Hirsch JF, Hoffman HJ, et al: Mechanical complications in shunts. Pediatr Neurosurg 17:2-9, 1991-1992

8. Virella AA, Galarza M, Masterman-Smith M, Lemus R, Lazareff JA: Distal slit valve and clinically relevant CSF overdrainage in children with hydrocephalus. Childs Nerv Syst 18:15-18, 2002

9. Whitehead WE, Riva-Cambrin J, Kulkarni AV, Wellons JC III, Rozzelle CJ, Tamber MS, et al: Ventricular catheter entry site and not catheter tip location predicts shunt survival: a secondary analysis of 3 large pediatric hydrocephalus studies. J Neurosurg Pediatr 19:157-167, 2017

\section{Disclosures}

The authors report no conflict of interest concerning the materials or methods used in this study or the findings specified in this table.

\section{Author Contributions}

Conception and design: Wetzel, Wheelus, Reisner, Chern. Acquisition of data: Wetzel, Waldman, Eshraghi, Wheelus, Chern. Analysis and interpretation of data: Wetzel, Waldman, Eshraghi, Wheelus, Chern. Drafting the article: Wetzel, Eshraghi, Chern. Critically revising the article: Wetzel, Texakalidis, Eshraghi, Reisner, Chern. Reviewed submitted version of manuscript: Wetzel, Texakalidis, Wheelus, Reisner, Chern. Approved the final version of the manuscript on behalf of all authors: Wetzel. Statistical analysis: Wetzel, Waldman, Texakalidis, Buster, Wheelus, Chern. Administrative/technical/material support: Wetzel, Reisner, Chern. Study supervision: Reisner, Chern.

\section{Supplemental Information \\ Online-Only Content}

Supplemental material is available with the online version of the article.

Supplemental Tables 1-3. https://thejns.org/doi/suppl/10.3171/ 2019.9.PEDS18579.

\section{Correspondence}

Jeremy S. Wetzel: Emory University School of Medicine, Atlanta, GA.jwetzel@emory.edu. 